\title{
Quality indicators on infection control in residential care homes for the elderly in Hong Kong
}

\author{
LW Chu *, FRCP (Lond, Edin, Glasg), FHKAM (Medicine) \\ Division of Geriatric Medicine, Department of Medicine, Li Ka Shing Faculty of Medicine, The University of Hong Kong, Pokfulam, \\ Hong Kong \\ *Corresponding author: Iwchu@hku.hk
}

Hong Kong Med J 2019;25:92-3

https://doi.org/10.12809/hkmj195087

The population of Hong Kong is ageing. The number of elderly persons aged $\geq 65$ years is projected to increase from 0.85 million in 2005 to 1.68 million in 2024. Moreover, there will be a rapid increase in the old-old population aged $\geq 85$ years, reaching 0.237 million in $2024 .^{1}$ These elderly individuals face substantial healthcare-related problems, including dementia, ${ }^{2-4}$ fragility hip fractures, ${ }^{5,6}$ frailty, ${ }^{7}$ carriage of multi-drug resistant organisms in residential care homes for the elderly (RCHEs), ${ }^{8}$ and provision of endof-life services. ${ }^{9}$ In 2017, there were 74257 residents in RCHEs in Hong Kong, which is equivalent to $6 \%$ of the elderly population. ${ }^{2}$ Approximately onethird of these residential care places are non-private (subvented). ${ }^{10} \mathrm{With}$ an increasing old-old population, the demand for RCHEs is expected to greatly increase. As elderly care is one of the most important government agendas, ageing in place should be given a higher priority. ${ }^{11}$ The Social Welfare Department is responsible for the issue of licences to all RCHEs and for regulating them through the Code of Practice. ${ }^{12}$ The quality standards in the Code of Practice focus mainly on the structure (eg, space, furniture, fire safety, equipment, and staff) and process of care (eg, record keeping, diet, nutrition, drug administration, urinary catheter care, feeding tubes and other nursing procedures, and infection control measures), but not outcomes (eg, mortality, morbidity, or hospital admissions) for their elderly residents. The infection control chapter in the Code of Practice was added after the 2003 SARS outbreak in Hong Kong. The aim was to improve infection control processes in RCHEs.

In the current issue of the Hong Kong Medical Journal, Wong et $\mathrm{al}^{13}$ report an audit study of the performance of infection control processes and procedures in $\mathrm{RCHEs}$, in relation to the quality standards set by the Code of Practice, from 2005 to 2014. This is the first study of its kind in Hong Kong. The authors found that there has been an improvement over time in terms of residents-tostaff manpower ratio, proportion of RCHEs with isolation rooms/areas, health records of staff and visitors, and infection control skills and practice. However, the authors also found that non-private
RCHEs often performed better than private RCHEs. For example, $93.0 \%$ of non-private RCHEs assigned nurses as Infection Control Officers (ICOs), whereas only $18.5 \%$ of private RCHEs followed this practice. In addition, $90.3 \%$ of non-private RCHEs provided isolation rooms/areas for infected residents, whereas only $73.3 \%$ of private RCHEs did so.

Some caution is recommended when considering these results. The authors assessed only two frontline care staff (the ICO and one care worker) per RCHE. ${ }^{13}$ Therefore, the results on the skills of infection control (ie, hand washing, donning and doffing of personal protective equipment, and using bleach solution for environmental disinfection) might not reflect the performance of the majority of the frontline care staff. A previous study by Chan et $\mathrm{al}^{14}$ reported that $46 \%$ of the staff in private $\mathrm{RCHEs}$ have a low education level. These care staff might perform less well than the ICOs. The authors also did not include data on the outcomes of infection control on elderly residents (ie, mortality, morbidity, hospitalisations). Among the different types of infections occurring in among elderly residents in RCHEs, influenza-like illnesses (including bacterial and viral infections) are the most common. In a study on 3857 residents in 46 RCHEs, the overall prevalence of all infections was $2.7 \%$, and the most common infections were respiratory tract infection (1.3\%). ${ }^{15}$ Hui et al ${ }^{16}$ reported an influenza-like illnessrelated mortality rate of $9.7 \%$ at 1 month or discharge from hospitals among elderly residents in RCHEs.

Further studies are recommended to evaluate the effect of infection control measures on the health outcomes of residents in RCHEs. Health outcomes including mortality, morbidity, hospitalizations should be included.

\section{Author contributions}

The author approved the final version for publication, and takes responsibility for its accuracy and integrity.

\section{Conflicts of interest}

As an editor of the journal, LW Chu was not involved in the peer review process. 


\section{References}

1. Census and Statistics Department, Hong Kong SAR Government. Available from: https://www.censtatd.gov.hk/ hkstat/sub/sp150.jsp?tableID=002\&ID=0\&productType $=8$. Accessed 23 Feb 2019.

2. Luk JK, Chan FH, Hui E, Tse CY. The feeding paradox in advanced dementia: a local perspective. Hong Kong Med J 2017;23:306-10.

3. Shea YF, Chu LW, Lee SC. A descriptive study of Lewy body dementia with functional imaging support in a Chinese population: a preliminary study. Hong Kong Med J 2017;23:222-30.

4. Chu LW. Challenges in the diagnosis and management of dementia in Hong Kong. Hong Kong Med J 2017;23:218-9.

5. Liu SK, Ho AW, Wong SH. Early surgery for Hong Kong Chinese elderly patients with hip fracture reduces short-term and long-term mortality. Hong Kong Med J 2017;23:374-80.

6. Cheung, MY, Ho AW, Wong SH. Post-fracture care gap: a retrospective population-based analysis of Hong Kong from 2009 to 2012. Hong Kong Med J 2018;24:579-83.

7. Wong CW. Frailty assessment: clinical application in the hospital setting. Hong Kong Med J 2018;24:623-8.

8. Chen H, Au KM, Hsu KE, et al. Multidrug-resistant organism carriage among residents from residential care homes for the elderly in Hong Kong: a prevalence survey with stratified cluster sampling. Hong Kong Med J 2018;24:350-60.

9. Luk JK. End-of-life services for older people in residential care homes in Hong Kong. Hong Kong Med J 2018;24:63-7.

10. Social Welfare Department, Hong Kong SAR Government. Social Welfare Department Review 2015-16 \& 2016-17. Available from: https:/www.swd.gov.hk/storage/asset/ section/1435/en/SWD_Review_Year_2015-16_and_201617-en.pdf. Accessed 23 Feb 2019.

11. Cheng CP. Elderly care as one of the important government policy agenda. Hong Kong Med J 2018;24:442-3.

12. Social Welfare Department (Licensing Office), Hong Kong SAR Government. Code of practice for residential care homes (elderly persons). Available from: https://www.swd.gov.hk/ doc/LORCHE/CodeofPractice_E_201303_20150313R3.pdf. Accessed 23 Feb 2019.

13. Wong CY, Ng T, Li T. Infection control in residential care homes for the elderly in Hong Kong (2005-2014). Hong Kong Med J 2019;25:113-9.

14. Chan TC, Luk JK, Chu LW, Chan FH. Low education level of nursing home staff in Chinese nursing homes. J Am Med Dir Assoc 2013;14:849-50.

15. Choy CS, Chen H, Yau CS, Hsu EK, Chik NY, Wong AT. Prevalence of infections among residents of Residential Care Homes for the Elderly in Hong Kong. Hong Kong Med J 2016;22:347-55.

16. Hui DS, Woo J, Hui E, et al. Influenza-like illness in residential care homes: a study of the incidence, aetiological agents, natural history and health resource utilisation. Thorax 2008;63:690-7. 